\title{
O QUE REVELA O DECÊNIO (2008-2018) DE PRODUÇÃO CIENTÍFICA SOBRE AVALIAÇÃO NA EDUCAÇÃO FÍSICA ESCOLAR?
}

\author{
WHAT DOES REVEALING THE DECADE (2008-2018) \\ OF SCIENTIFIC PRODUCTION ABOUT EVALUATION \\ IN SCHOOL PHYSICAL EDUCATION? \\ ¿LO QUE REVELA LA DÉCADA (2008-2018) DE LA \\ PRODUCCIÓN CIENTÍFICA EN RELACIÓN CON \\ LA EVALUACIÓN EN EDUCACIÓN FÍSICA?
}

Fabiana de Paula Pereira ${ }^{1}$

KLEBER TUXEN CARNEIRO ${ }^{2}$

BRUNo Adriano Rodrigues DA Silva ${ }^{3}$

FÁBio Pinto Gonçalves dos Reis ${ }^{4}$

NATHÁlia MARIA RESENDE ${ }^{5}$

${ }^{1}$ Universidade Federal de Lavras (UFLA), Lavras/MG-Brasil

${ }^{2}$ Universidade Federal de Lavras (UFLA), Lavras/MG-Brasil

${ }^{3}$ Universidade Federal do Estado do Rio de Janeiro (UNIRIO),

Rio de Janeiro/RJ-Brasil

${ }^{4}$ Universidade Federal de Lavras (UFLA), Lavras/MG-Brasil

${ }^{5}$ Universidade Federal de Lavras (UFLA), Lavras/MG-Brasil

RESUmo Nesta pesquisa qualiquantitativa, procurou-se investigar a produção do conhecimento relativo à Avaliação para o campo da Educação Física, identificando e quantificando as produções científicas contidas em revistas eletrônicas da área de conhecimento da Educação e da subárea da Educação Física. Constatou-se o total de 11 revistas dos Qualis A1, A2 e B1 e 27 artigos, sendo 11 da Educação e 16 da Educação Física, os quais foram agrupados nas categorias analíticas "Currículo e Documentos Institucionais", "Procedimentos e Experiências Avaliativas" e "Balanço de Produção". As lacunas históricas nessa literatura especializada engendram certa fragilidade ao campo da formação, por efeito a necessidade de expansão e aprofundamento de estudos que se dediquem ao tema, a julgar pelo próprio número circunscrito de produções que identificamos. Por fim, acreditamos que esta investigação poderá subsidiar futuras pesquisas, ao mesmo tempo em que revela a necessidade de se redimensionar os processos avaliativos no interior da Educação/Educação Física.

Palavras-chave: Avaliação; Educação Física; Revisão Bibliográfica. 
AbSTRACT This qualitative and quantitative research sought to investigate the production of knowledge related to Evaluation for the field of Physical Education, identifying and quantifying the scientific productions contained in electronic journals in the area of knowledge of Education and the sub-area of Physical Education. There was a total of 11 journals of Qualis A1, A2 and B1 and 27 articles, 11 of which on Education and 16 on Physical Education, which were grouped into the analytical categories "Curriculum and Institutional Documents", "Procedures and Evaluative Experiences" and "Production Balance". The historical gaps in this specialized literature give rise to certain fragility in the field of formation, in effect the need for expansion and deepening of studies dedicated to the theme, judging by the very circumscribed number of productions we have identified. Finally, we believe that this investigation may subsidize future researches, while revealing the need to resize the evaluative processes within the Education and Physical Education.

Keywords: Evaluation; Physical Education; Literature review.

RESUMEN En este investigación cualitativa y cuantitativa buscó investigar la producción de conocimiento relacionado con la Evaluación para el campo de la Educación Física, identificando y cuantificando las producciones científicas contenidas en revistas electrónicas en el área del conocimiento de la Educación y la subárea de Educación Física. Hubo un total de 11 revistas de Qualis A1, A2 y B1 y 27 artículos, 11 de los cuales fueron de Educación y 16 de Educación Física, que se agruparon en las categorías analíticas "Plan de estudios y documentos institucionales", "Procedimientos y experiencias de evaluación" y "Balance de producción". Las brechas históricas en esta literatura especializada dan lugar a una cierta fragilidad en el campo de la formación, por efecto, la necesidad de expansión y profundización de los estudios dedicados al tema, a juzgar por el número muy circunscrito de producciones que hemos identificado. Por fin, creemos que esta investigación puede apoyar investigaciones futuras, al tiempo que revela la necesidad de redimensionar los procesos de evaluación en el interior de la Educación/Educación Física.

Palabras Clave: Evaluación; Educación Física; Revisión bibliográfica.

\section{INTRODUÇÃO}

$\mathrm{O}$ ato de avaliar exige distanciamento e algum nível de elaboração em sua execução. Ele é constituído com base nas representações dos indivíduos e pertence, portanto, ao processo educacional e tudo aquilo que envolve o cotidiano da vida em sociedade. Nesse sentido, é possível afirmar - com relativa segurança - que o ato de avaliar configura-se como uma prática: delicada, multifacetada e ampla, em razão de sua natureza complexa e multifatorial.

Neste artigo, contudo, tratamos o ato de avaliar sobre a circunscrição da instituição escolar. Logo, ele pressupõe uma relação entre quem realiza a avaliação, quem é avaliado e o recurso que é utilizado por quem efetua a avaliação, algo pouco presente, por um conjunto de razões, no cotidiano das instituições escolares. O que notamos, normalmente, ao contrário desse entendimento, é uma associação - pouco elaborada e linear - entre avaliação e classificação realizada por intermédio da atribuição de notas e conceitos (HOFFLMANN, 2006). 
Nesse caminho, avaliar não seria uma ação pontual, descontextualizada e desconecta dos processos cognitivos, sociais e culturais na qual o indivíduo está inserido, mas, sobremaneira, um espaço de construção coletiva em que a apropriação do conhecimento historicamente construído é evidenciada, com vistas a aferir uma experiência formativa (LUCKESI, 2002), observando "o esforço do aluno de aprender", tal qual "o do professor de mudar suas práticas, caso os alunos apresentem dificuldades de aprendizagem" (DARIDO, 2012, p. 131).

Ora, se no âmbito geral falar de avaliação no espaço escolar suscita desafios teóricos e metodológicos em relação à organização do trabalho docente, o cenário fica ainda mais complexo em uma disciplina, tal qual a Educação Física, que possui a finalidade, pelo menos em tese, de proporcionar uma apropriação crítica da cultura corporal de movimento, “(...) visando a formar o cidadão que possa usufruir, compartilhar, produzir, reproduzir e transformar as formas culturais do exercício da motricidade humana” (BETTI, 2013, p. 64).

Nesse caso, como avaliar o cumprimento ou não de tais objetivos colocados de modo tão abrangente? Como saber se um aluno compartilha culturalmente uma modalidade esportiva ou transforma a prática da ginástica, conforme as necessidades do seu cotidiano? Decerto essas não são respostas de fácil elaboração, mesmo porque na instituição escolar, em geral, cabe à Educação Física, em função de sua constituição histórica, fundamentada em preceitos médicos (sob o prisma da assepsia), principalmente - mas não apenas, basta se recordar da repercussão do movimento militarista e de esportivização, cujos efeitos ainda são observados no interior da área -, desenvolver um conjunto de práticas que são determinadas pela aptidão física de cada indivíduo: possuir ou não possuir aptidão para o desenvolvimento das práticas corporais, em geral, é isto que se avalia (BETTI, 2013; CARNEIRO et al., 2016).

Mas por que isso ocorre? Por qual razão, via de regra, avaliar em Educação Física se resume à ideia de aptidão física? Provavelmente, uma compreensão elaborada da composição histórica dessa subárea de conhecimento ajude a responder essa indagação, contudo, outra síntese pode ser construída, mesmo que funcionando como problemática de pesquisa: seria a produção do conhecimento científico a respeito da avaliação em Educação Física um fator de interferência na organização do trabalho docente? Somado a ela, acrescenta-se, o que essa produção revela?

Por efeito dessa problemática, nosso objetivo neste artigo é cotejar a produção científica relativa à avaliação em Educação Física escolar difundida em periódicos eletrônicos de maior impacto na área da Educação, bem como, na subárea da Educação Física, considerando sua interface epistemológica, no período de 2008 a 2018. Para tanto, desenvolvemos uma pesquisa de natureza quantitativa e qualitativa que recorreu à análise de conteúdo para elaborar as categorias de análise e investigar o cenário inicialmente mapeado por intermédio de dados quantitativos, conforme doravante.

\section{Metodologia}

A pesquisa mista, quantitativa e qualitativa, ocorre quando há coexistência na natureza das interpretações acerca de um conjunto de dados (DUARTE et al., 2009). Os métodos 
mistos, nesse sentido, proporcionam a construção de mais evidências para o estudo de um problema de pesquisa e, por isso, contribuem com a sua resolução, ao menos em tese (CRESWELL; CLARK, 2013).

No contexto desta investigação, pode-se dizer que a natureza quantitativa, decorre da mensuração numérica, de forma absoluta e relativa, de produções sobre a avaliação em Educação Física Escolar, como forma de identificar as prevalências e traçar projeções para a realização de pesquisas sobre Avaliação em Educação Física Escolar. Já a natureza qualitativa, sobrevém da elaboração das categorias que são extraídas do material empírico a fim de tipificá-lo, algo que fizemos com base em análise de conteúdo (BARDIN, 2009).

Em síntese, trata-se de um entendimento investigativo alinhado à perspectiva de Johnson et al. (2007), para quem a associação dessas duas naturezas de pesquisa tende a ampliar e aprofundar o entendimento sobre determinado fenômeno. Logo, realizar um estudo por intermédio de publicações em periódicos científicos da Educação e da Educação Física nos parece um caminho auspicioso, na direção de compreender os avanços, perspectivas e desafios para o tema da Avaliação, de uma maneira geral, e da avaliação em Educação Física de modo específico (DOS SANTOS et al., 2018). A seguir, vejamos, passo a passo, cada uma das etapas metodológicas.

Inicialmente, o levantamento dos dados (artigos científicos) considerou a Plataforma Sucupira, ${ }^{1}$ vinculada à Coordenação de Aperfeiçoamento de Pessoal de Nível Superior (CAPES), cuja finalidade é disponibilizar informações sobre o Sistema Nacional de Pós-Graduação (SNPG). Acessando tal base de dados, procuramos as revistas da área (38) da Educação e da subárea (vinculada à área 21) Educação Física, respectivamente, em que o evento de classificação estivesse circunscrito ao quadriênio 2013-2016. ${ }^{2}$

A partir do preenchimento de todos os campos necessários para acessar as revistas da área e subárea já mencionadas, bem como, a avaliação do Qualis $^{3}$ de cada uma delas, foi gerada uma lista no programa Microsoft Excel contendo o ISSN eletrônico e físico, nome do periódico e sua estratificação. Para fins desta pesquisa, utilizamos apenas os periódicos de maior estratificação (A1, A2 e B1), em razão de seu maior impacto científico. Compete-nos dizer que a estratificação de uma revista, seu Qualis, é estabelecida por um conjunto de procedimentos empregados pela CAPES para determinar a qualidade dessa produção científica, bem como, sua circulação e impacto (CAPES, 2009). Trata-se de um dos "instrumentos fundamentais para a avaliação do quesito produção intelectual, agregando [supostamente] o aspecto quantitativo ao qualitativo" (BARATA, 2016, p. 14).

Em seguida, ao adentrarmos nos periódicos verificamos uma baixa incidência de artigos científicos sobre Avaliação. Em razão disso, reorganizamos as buscas empregando descritores cujo teor se aproximasse e retratasse pontualmente o mote central do estudo. Sendo assim, definiram-se os seguintes unitermos: "Avaliação da Aprendizagem", "Avaliação em Educação Física" e "Processos Avaliativos". Corolário a isso, iniciou-se a "navegação" nos periódicos, passando a conferi-los, volume por volume, isto é observando cada uma das

1 Maiores informações: https://sucupira.capes.gov.br/sucupira/

2 Utilizamos esse quadriênio como referência para a construção do material empírico, em função do momento em que a pesquisa foi realizada, no primeiro semestre de 2019. O fato de uma nova avaliação estar em curso não foi considerado.

3 Estratificação utilizada pela Capes para classificar os periódicos científicos. 
edições. Com efeito, verificamos uma incidência maior de artigos científicos entre os anos de 2008 a 2018.

Na sequência, a partir da seleção das revistas e dos artigos científicos, iniciamos o processo de leitura flutuante que consiste basicamente em estabelecer contato com o material empírico, extraindo impressões, representações, entre outros elementos (FRANCO, 2008). Para tanto, observaram-se as unidades de registros. No caso desta investigação, referem-se às palavras e temas que se relacionem à Avaliação - e as unidades de contexto, que dizem respeito à parte mais ampla do conteúdo analisando documentos, os personagens, as instituições e recursos atrelados às práticas avaliativas, uma espécie de "pano de fundo" que imprime significado às Unidades de Análise (BARDIN, 2009).

Por efeito, culminou-se na fase que antecedeu à análise, momento em que separamos os trabalhos que guardavam relação direta com o fito da pesquisa, observando as regras de homogeneidade e exaustividade (leitura na íntegra e, por vezes, repetidamente do material empírico), gerando conjecturas, das quais conduzir-nos-iam às definições das categorias, pináculo da análise de conteúdo (FRANCO, 2008). Nessa esteira, realizamos um trabalho analítico junto às produções, com base na análise de conteúdo dos artigos científicos (dimensão qualitativa) e análise descritiva de dados quantitativos (dimensão quantitativa).

Tal forma de análise possibilitou a inferência sobre as condições de produção dos artigos, a classificação e posterior tipificação do material empírico (BARDIN, 2009). Os resultados, por sua vez, conduziram à formulação de três categorias de análise, quais sejam:

"Currículo e Documentos Institucionais", categoria que reúne trabalhos que contemplam a avaliação, analisando as matrizes curriculares dos cursos de formação inicial em Educação Física, assim como artigos que examinaram documentos institucionais ${ }^{4}$ relativos à educação básica ao abrigo da subárea da Educação Física, o que nos permitiu ponderar a presença ou ausência da temática no interior dos processos formativos;

"Procedimentos e Experiências Avaliativas", agrupamento que congrega artigos dos quais o teor aborda, descreve ou relata experiências relativas aos métodos avaliativos sob a percepção de professores e alunos em relação às práticas avaliativas;

"Balanço de Produção", última categoria de análise que consiste basicamente em uma produção sob princípios metodológicos de revisão sistemática e outra dedicada a uma investigação literária sobre as possibilidades e perspectivas referentes à temática avaliação em Educação Física.

Trata-se de categorias elaboradas em conformidade e observância aos critérios de inclusão e exclusão, exclusividade, homogeneidade e confiabilidade (CARLOMAGNO; ROCHA, 2016). Doravante, passemos aos resultados e reflexões provenientes deles.

\section{RESULTADOS E DISCUSSÕES}

Conforme a descrição metodológica exposta na seção anterior, encontrou-se na Plataforma Sucupira um total de 284 revistas cuja estratificação enquadra-se em A1, A2 e

4 Para Rodrigues et al. (2004), os documentos institucionais são aqueles capazes de gerar uma visibilidade e "valor" ao público educacional, contribuindo como um indicador da qualidade de ensino e demais demandas de uma instituição pedagógica. 
B1, distribuídas entre a área da Educação e a subárea da Educação Física. Por efeito do uso dos descritores e da investigação em cada periódico, esse número diminuiu para 11. Sendo que houve a prevalência de revistas da área de Educação, com o percentual de $63,6 \%$, totalizando sete revistas, enquanto a Educação Física apresenta apenas 36,4\%, o que totaliza quatro revistas.

Em se tratando da distribuição do total de revistas da área da Educação, em relação ao Qualis CAPES, verificamos seis revistas estratificadas em B1, seguida de apenas uma revista em estratificação A1, sendo inexistente a presença de artigos sobre Avaliação em revistas estratificadas em A2. Já no âmbito da Educação Física, as quatro revistas encontradas estão estratificadas em A2, não existindo, portanto, revistas estratificadas em A1 e B1. O cenário cotejado poderá ser conferido na Tabela 1.

Tabela 1 - Distribuição do Qualis entre as Áreas

\begin{tabular}{lcccc|cc}
\hline \multirow{2}{*}{ QUALIS } & \multicolumn{2}{c|}{ ÁREA } & \multicolumn{2}{c}{ TOTAL } \\
\cline { 2 - 8 } & $\mathrm{n}$ & $\%$ & $\mathrm{~N}$ & $\%$ & $\mathrm{~N}$ & $\%$ \\
\hline A1 & 1 & 100 & 0 & 0,0 & 1 & 100 \\
A2 & 0 & 0,0 & 4 & 100 & 4 & 100 \\
B1 & 6 & 100 & 0 & 0,0 & 6 & 100 \\
\hline TOTAL & 7 & 63,6 & 4 & 36,4 & 11 & 100 \\
\hline
\end{tabular}

Fonte - Tabela construída pelos autores.

No tocante ao processo sistemático de busca dos artigos científicos nesses periódicos supracitados que compõem a pesquisa, foram encontradas 29 obras, validando-se apenas 27, uma vez que dois artigos não tratavam de Avaliação no contexto escolar da Educação Física, distanciando-se, assim, do delineamento instituído para o estudo. Dos 27 artigos, 11 são provenientes de periódicos da área da Educação e 16 relativos às revistas da subárea Educação Física. Vale ressaltar que a revista intitulada: "Revista Brasileira de Ciências do Esporte", alocada no interior dessa subárea, não permitiu acesso para volumes inferiores ao ano de 2013. Fizemos destaque a esse fato, tendo em vista que possam existir produções nesse ínterim que não foram contabilizadas por nosso estudo, em razão de tal restrição.

Analisando o cenário aferido, do total de 11 artigos ao abrigo da área Educação, a maioria, nove deles, pertence à estratificação B1, enquanto apenas dois pertencem ao estrato A1. No entanto, dos 16 artigos da subárea da Educação Física, todos eles estão estratificados em revistas A2. Muito provavelmente, a constatação da ausência de artigos sob estratificação A1 nessa subárea se relacione ao que Correia et al. (2012) identificaram como uma "dificuldade natural" de publicação nessa estratificação, em razão da "jovialidade acadêmica" da Educação Física.

A Tabela 2 sintetiza o conjunto de informações agrupadas por descritores, vejamos: 
Tabela 2 - Número absoluto e relativo de artigos selecionados por descritores, divididos por área

\begin{tabular}{cccc}
\hline \multirow{2}{*}{ Descritores } & \multicolumn{2}{c}{ Área } & \multirow{2}{*}{ TOTAL } \\
\cline { 2 - 3 } & Educação N (\%) & Educação Física N (\%) & \\
\hline Avaliação da Aprendizagem & $3(27,3)$ & $4(25,0)$ & $7(25,9)$ \\
Avaliação em EDF & $3(27,3)$ & $8(50,0)$ & $11(40,8)$ \\
Processos avaliativos & $5(45,4)$ & $4(25,0)$ & $9(33,3)$ \\
\hline TOTAL & $11(100)$ & $16(100)$ & $27(100)$ \\
\hline
\end{tabular}

Fonte - Tabela construída pelos autores.

Constata-se na Tabela 2 que a maior parte dos artigos encontrados na área da Educação corresponde ao descritor "Processos Avaliativos", enquanto, nas revistas da subárea Educação Física nós verificamos a predominância do descritor "Avaliação em Educação Física".

Em termos gerais, ao observarmos a frequência dos artigos em revistas da Educação e da Educação Física, notamos uma verossimilhança em termos de proporcionalidade. No entanto, ao analisarmos mais detidamente a prevalência dos resultados no âmbito da subárea Educação Física, pode-se inferir que a especificidade da avaliação na organização do trabalho docente influenciou no resultado encontrado, isso porque, essa subárea, historicamente, guarda relações epistemológicas com a Pedagogia e com a própria instituição escolar, algo que a coloca diante da tarefa, ao menos em tese, de avaliar (compreendido como mensurar, por vezes) os processos educacionais (DARIDO, 2012).

Nas revistas da área da Educação, por sua vez, verificou-se a predominância do descritor "Processos Avaliativos", muito em função, assim acreditamos, de ser a Avaliação (epistemologicamente), naquele contexto acadêmico, uma temática de pesquisa relevante, organizada no campo científico e com vasta produção sobre diferentes assuntos que cercam a Avaliação, desde as políticas, dos docentes e discentes, passando pelos instrumentos utilizados em larga e pequena escala e pelas experiências desenvolvidas, relatos, por assim dizer (BERTAGNA; SORDÍ, 2016).

Pois bem, após selecionarmos os artigos encontrados nas revistas, alinhá-los aos descritores, delineou-se os mesmos conforme o ano de publicação no decênio 2008-2018. Os dados encontram-se na Tabela 3.

Com base nas expressões numéricas contidas em questão, algumas inferências podem ser arquitetadas, a primeira delas diz respeito à proporcionalidade entre os artigos produzidos na Área da Educação e na Subárea Educação Física ao longo do interstício pesquisado, com exceção ao ano de 2016, em que se verifica um descompasso numérico entre as produções, já que elas se intensificaram na subárea Educação Física, cujos limites deste estudo não nos permitem saber a razão. 
Tabela 3 - Número absoluto e relativo de artigos selecionados por ano, dividido por área

\begin{tabular}{cccc}
\hline \multirow{2}{*}{ ANO } & \multicolumn{2}{c}{ Área } & \multirow{2}{*}{ TOTAL } \\
\cline { 2 - 3 } & Educação N (\%) & Educação Física N $(\%)$ & $1(3,7)$ \\
2008 & $1(9,1)$ & $0(0,0)$ & $1(3,7)$ \\
2009 & $0(0,0)$ & $1(6,25)$ & $3(11,1)$ \\
2010 & $1(9,1)$ & $2(12,5)$ & $1(3,7)$ \\
2012 & $1(9,1)$ & $0(0,0)$ & $0(0,0)$ \\
2013 & $0(0,0)$ & $0(0,0)$ & $2(7,4)$ \\
2014 & $1(9,1)$ & $1(6,25)$ & $1(3,7)$ \\
2015 & $0(0,0)$ & $1(6,25)$ & $2(7,4)$ \\
2016 & $0(0,0)$ & $2(12,5)$ & $5(18,5)$ \\
2017 & $1(9,1)$ & $4(25,0)$ & $2(7,4)$ \\
2018 & $1(9,1)$ & $1(6,25)$ & $9(33,4)$ \\
\hline TOTAL & $5(45,4)$ & $4(25,0)$ & $27(100)$ \\
\hline
\end{tabular}

Fonte - Tabela construída pelos autores.

Outra constatação advém da prevalência de trabalhos produzidos, em 2018, sendo cinco artigos na área da Educação, o que corresponde a 45,4\% dos achados na área e quatro artigos relacionados à subárea Educação Física, o equivalente a 25\% dos achados. Trata-se de um expressivo avanço, caso consideremos que o tema da Avaliação na Educação é organizado, apesar de sua "jovialidade”, e que na Educação Física ele é ainda mais recente e, por efeito, menos organizado (BERTAGNA; SORDÍ, 2016; DOS SANTOS, 2018). Todavia, é inegável que tais produções, tanto na Educação quanto na Educação Física, ainda possua um "longo caminho" a ser percorrido, na direção de mobilizar a produção de sentido/significado da aprendizagem como um todo e de organizar o trabalho pedagógico na Educação Física para reverter o quadro de pouca preocupação com essa temática (CARMINATTI; BORGES, 2012; GATTI, 2002; MATSUMOTO; AYOUB, 2018).

Avançando na apresentação e análise dos resultados de nossa investigação, identificamos na tabela a seguir os assuntos (circunscritos à temática da Avaliação de uma maneira geral e à avaliação em Educação Física de modo específico), dos quais os artigos examinaram. Para tanto, recorremos à análise de conteúdo - conforme detalhado na seção pertinente a descrever a metodologia - proposta por Bardin (2009), resultando nas seguintes categorias de análise: 1) Currículo e Documentos Institucionais; 2) Procedimentos e Experiências Avaliativas; e 3) Balanço de Produção. A distribuição quantitativa dessas categorias pode ser conferida na Tabela 4.

Em linhas gerais, observa-se que a maioria dos trabalhos descobertos por nosso estudo encontra-se ao abrigo da categoria "Procedimentos e Experiências Avaliativas". Nessa categoria, foram encontrados sete artigos relativos à área da Educação $(63,65 \%)$ e 12 artigos na área da Educação Física (75\%). Por sua vez, a categoria "Currículo e Documentos Institucionais" foi a responsável por agrupar 27,30\%, três dos artigos publicados na Educação e $18,75 \%$ (dois) nas revistas da Educação Física. Enquanto na categoria "Balanço de Produção", encontramos apenas um artigo (9,05\%) nas revistas da Educação e um (6,25\%) artigo na Educação Física. 
Tabela 4 - Número absoluto e relativo de artigos distribuídos por categoria de análise, dividido por área

\begin{tabular}{cccc}
\hline \multirow{2}{*}{ Categoria de análise } & \multicolumn{2}{c}{ Área } & \multirow{2}{*}{ TOTAL } \\
\cline { 2 - 3 } & Educação N (\%) & Educação Física N (\%) & $6(22,20)$ \\
\hline $\begin{array}{c}\text { Currículo e Documentos } \\
\text { Institucionais }\end{array}$ & $3(27,30)$ & $3(18,75)$ & $19(70,40)$ \\
$\begin{array}{c}\text { Procedimentos e Experiências } \\
\text { Avaliativas }\end{array}$ & $7(63,65)$ & $12(75,0)$ & $2(7,40)$ \\
\hline Balanço de Produção & $1(9,05)$ & $1(6,25)$ & $27(100)$ \\
\hline TOTAL & $11(100)$ & $16(100)$ &
\end{tabular}

Fonte - Tabela construída pelos autores.

Pois bem, na direção de aprofundar as discussões, bem como, estabelecer algumas reflexões e inferências - qual propõe a análise de conteúdo - se buscará tratar separadamente de cada uma das categorias de análise, a partir desse momento.

\section{CURRÍCULO E DOCUMENTOS INSTITUCIONAIS}

Para Davini (1994), o currículo se trata de um documento pedagógico no qual a escola se orienta para promover uma aprendizagem de forma sistêmica. Nessa linha, passa a ser "toda a experiência proposta pela escola ou a partir dela e que, de múltiplas maneiras, subjetiva discentes e docentes" (NEIRA; JÚNIOR, 2016, p. 190), portanto, “deve ser flexível e adaptado às diversas situações, suscetível de ser constantemente avaliado e melhorado de acordo com as experiências" (DAVINI, 1994, p. 285).

Sabemos que é ao longo da escolarização e da formação em nível superior que o discente em processo formativo tem acesso aos conceitos, atitudes e procedimentos de avaliação que, por efeito desse contato (em sua forma e conteúdo), reverberam no desenvolvimento do trabalho pedagógico, durante sua atuação profissional nas instituições escolares (MELO et al., 2010). Porém, no entendimento de Dos Santos e Maximiano (2013), a formação inicial está carente de modelos explicativos acerca dos processos de avaliação, algo que foi evidenciado por intermédio de uma pesquisa sobre a Avaliação nos cursos de formação de professores de Educação Física em oito países da América Latina. De acordo com os resultados desta pesquisa, apenas 80 disciplinas sobre Avaliação foram encontradas na amostra e destas, somente 45 apresentam relação com o contexto escolar (PAULA et al., 2018).

Essa mesma constatação foi feita no Brasil por de Stieg et al. (2018) e Dos Santos et al. (2018), uma vez que esses autores confirmaram a escassez da temática no interior das matrizes curriculares dos cursos de formação inicial respectivamente, notemos o detalhamento: i) das 63 instituições federais brasileiras, 43 ofertam o curso de licenciatura em Educação Física, sendo que apenas oito deles possuem uma disciplina obrigatória dedicada ao estudo da Avaliação, tendo como referência as três etapas da educação básica (Educa- 
ção Infantil, Ensino Fundamental e Médio), contudo, com menor incidência na Educação Infantil e Anos Iniciais do Ensino Fundamental; ${ }^{5}$ ii) na região sul e norte do país não foram verificadas a presença de disciplinas sobre Avaliação nas instituições formadoras.

Tal conjuntura apresentada, inclusive, encontra-se em desacordo com aquilo que está normatizado no Artigo 25, Inciso V, alínea a da Lei de Diretrizes e Bases (LDB) nº 9.394/96 que menciona a Avaliação como contínua e cumulativa no desempenho do aluno, prevalecendo os aspectos qualitativos no decorrer do período avaliado. Malgrado essa premente discussão, a respeito da frágil presença de disciplinas acadêmicas sobre Avaliação nos cursos de formação de professores de Educação Física, não elimina a possibilidade de que experiências escolares bem-sucedidas envolvendo a Avaliação possam ocorrer, conquanto pudessem ser robustecidas caso elas compusessem o quadro formativo.

O estudo de Diniz e Amaral (2009) analisa, a partir da comparação, os documentos institucionais de uma escola com a organização do tempo seriada e outra em ciclos de aprendizagem, discorrendo sobre a concepção da Educação Física, inclusive no que diz respeito à Avaliação, nessas instituições. Sob a ótica da escola seriada, a Educação Física enfatiza a dimensão quantitativa da Avaliação, conforme as aspirações de desenvolvimento da aptidão física dos "futuros trabalhadores", valendo-se da mensuração e quantificação dos conteúdos essenciais para motivar a aprendizagem (DINIZ; AMARAL, 2009).

Já em relação às análises da escola organizada, em ciclos de formação, a concepção de Educação Física está embasada "em ideias construtivistas e conceitos de que a aprendizagem e conhecimento ocorrem por processo gradual, ou seja, os sujeitos necessitam de tempos diferenciados para completar cada fase do processo" (DINIZ; AMARAL, 2009, p. 247), uma vez que ela "(...) ganha novas perspectivas de realização dos seus conteúdos, com a possibilidade de interação entre os alunos e professores" (DINIZ; AMARAL, 2009, p. 254).

Trata-se de uma discussão interessante ao se comparar ambas as perspectivas de organização escolar, todavia, demandariam um aprofundamento em suas inferências de análise, contudo, os limites instituídos a este trabalho não permitem tal incursão analítica.

A seguir, apresentaremos outra categoria de análise mapeada a partir dos dados aferidos por nossa investigação.

\section{Procedimentos E eXPeriênCIAS AVAliativas}

Classificamos como parte desta categoria os artigos decorrentes de experiências avaliativas em instituições escolares, concernente aos processos de ensino-aprendizagem em um dado espaço-tempo, um procedimento (metodológico) similar ao adotado por Fernandes (2007).

$\mathrm{Na}$ acepção de Larrosa (2002, p. 21) "a experiência é tudo aquilo o que nos passa, o que nos acontece, o que nos toca". Com efeito, trata-se de acontecimentos significativos ao longo da existência, por isso, complementa o autor, que, "o sujeito da experiência é um

5 Provavelmente isso ocorre em função das discussões sobre a inserção do professor de Educação Física nestas etapas, algo que é considerado por Ayoub (2001) como um avanço, em que pese à necessidade de maiores discussões sobre a ocupação (profissional) dos espaços nestas aulas, já que, de acordo com currículos de várias escolas e creches, é competência do professor "generalista" ministrar esse componente curricular. 
sujeito 'ex-posto' que se define por sua passividade, por sua receptividade, por sua disponibilidade, por sua abertura” (LARROSA, 2002, p. 24).

Nessa esteira de reflexão, pensar sobre práticas avaliativas é de algum modo refletir quanto às marcas formativas que forjam um professor, desde a escolarização, formação inicial e continuada, até o decurso longitudinal da carreira docente, de igual modo, das experiências que virão a ser desenvolvidas no interior de seu trabalho pedagógico (HOFFMANN, 2006).

Luckesi (2002, p. 84) anota que: “Avaliar é o ato de diagnosticar uma experiência, tendo em vista reorientá-la para produzir o melhor resultado possível; por isso, não é classificatória nem seletiva; ao contrário, é diagnóstica e inclusiva". Ainda, de acordo com o referido autor, a conciliação de uma concepção de Avaliação e as práticas avaliativas cotidianas produzem frequentes "imbróglios", já que, via de regra, confunde-se instrumentos de coleta de dados com instrumentos de avaliação, o que dificulta ainda mais as tentativas de superação do equívoco de praticar exames e chamá-los de avaliação (LUCKESI, 2002).

Para Dos Santos e Maximiano (2013), ao atribuir um tipo de instrumento é preciso também imputar sentido e significado "à perspectiva epistemológica que lhe oferecem suporte", dado que um recurso mal empregado pode interferir negativamente em todo o processo (avaliativo) educacional (PAULA et al., 2018, p. 815). Eles (lê-se os recursos), segundo Luckesi (2000, p. 12), necessitam ser "adequados ao tipo de conduta e de habilidade que estamos avaliando; adequados aos conteúdos planejados; adequados à linguagem e precisão da comunicação" a fim de que não comprometam o processo de aprendizagem.

No âmbito da subárea Educação Física, ao recorrer a determinados instrumentos avaliativos - conscientes ou não - os professores assumem e se alinham com as práticas avaliativas constituídas a partir de concepções higienistas do final do século XIX, que enfatizam a aquisição de aptidão física valendo-se de procedimentos, nos quais "os indivíduos estavam orientados em princípios anatomofisiológicos, buscando a criação de um homem obediente, submisso e acrítico à realidade brasileira" (SOARES, 2012, p. 1).

Isso não fica restrito a essa concepção de Educação Física, e por efeito de Avaliação em Educação Física, uma vez que até mesmo no interior das proposições pedagógicas eclodidas, após a década de 1970, a presença do tema Avaliação fica aquém do necessário. Para ratificar essa conjectura, examinamos a presença da Avaliação nas principais obras que figuram na condição de aporte teórico para as perspectivas de ensino, na direção de mapear o espaço que o tema ocupa em cada uma delas. Para tanto, analisamos as seguintes proposições de ensino: Desenvolvimentista (TANI et al., 1988), Construtivista (FREIRE, 1997), Sistêmica (BETTI, 1991), Cultural (DAOLIO, 2004), Crítico-superadora (SOARES, et al., 1992) e Psicomotricidade (LE BOULCH, 1992). Os resultados evidenciaram que apenas duas das perspectivas investigadas apresentam discussões a respeito do tema.

Sob o ponto de vista da abordagem construtivista, tendo Freire (1997) na qualidade de principal expoente, um dos maiores problemas em avaliar consiste em coadunar os aspectos cognitivos e motor integradamente, um grande desafio, dada a complexidade do contexto pedagógico. Para o autor supracitado, uma simples atividade como o "pular corda" permite diversas considerações que podem ser feitas pelo professor, já que nela há expressões evidentes produzidas como: a indecisão, a impaciência e o cansaço. Diante dessa atividade, é 
possível ainda avaliar "a afetividade, a motricidade, a sociabilidade e a cognição", além de permitir uma facilidade em avaliar turmas grandes, possibilitando propiciar uma reflexão, por intermédio da observação (FREIRE, 1997, p. 203).

Quanto à segunda perspectiva de ensino (leia-se a abordagem crítico-superadora), na qual se constatou espaço dedicado ao tema avaliação, Soares et al. (1992) compreendem as avaliações enquanto formas de interpretação das heranças culturais, que se expressam por intermédio da cultura corporal, diferenciando-se, assim, de turma para turma. Por essa razão, o processo vai muito além, a começar pelo projeto histórico, ou seja, conhecer o público pelo qual irá direcionar com a sociedade e suas concepções. Após o reconhecimento dos sujeitos envolvidos, é propício: considerar aspectos que levem em conta a observação dos elementos condizentes que se expressam no decorrer das aulas; superar as práticas avaliativas mecânicas (testes, seleção, detecção); adotar práticas avaliativas criativas e reiterativas buscando propor debates e críticas mediados por conflitos próprios do processo ensino-aprendizagem. Em síntese: “(...) o redimensionamento do processo de ensino, na emissão do conceito, nos dados qualitativos e quantitativos, na utilização de instrumentos e na interpretação do insucesso e do erro" (SOARES et al., 1992, p. 106).

A conjuntura aqui verificada leva-nos a inferir que é premente ampliar os debates e as margens da compreensão do lugar da Avaliação na formação (inicial e continuada), tal qual no desenvolvimento do trabalho pedagógico desempenhado pela Educação Física na escola, muito provavelmente a advertência de Luckesi (2002) a respeito da confusão entre instrumentos de coleta de dados e instrumentos de avaliação seja iminente no interior dessa subárea, basta ver seu (lastro) histórico.

Quanto ao debate que envolve os instrumentos avaliativos, destacam-se algumas experiências desdobradas em artigos científicos cotejados, são elas: a utilização de um blog para desenvolver o conteúdo de capoeira nas aulas de Educação Física (SILVA et al., 2013); o festival como possibilidade formativa, a fim de ampliar o cabedal dos alunos em relação ao conteúdo de "danças" (CARBINATTO et al., 2018); a autoavaliação (VARGAS, 2017); a diversidade de recursos empregados por 14 professores para o ensino de "ginástica" (CARBINATTO; NUNOMURA 2016); a utilização de registros imagéticos e de matérias televisivas (BETTI, 2010) e; as possibilidades avaliativas advindas do portfólio sobre "jogos e brincadeiras" (MELO et al., 2010).

A variação de instrumentos avaliativos é um importante indicador para o processo de ensino, com implicações para a aprendizagem (HOFFMANN, 2006). Por efeito da variedade de recursos, engendram-se registros como forma avaliativa, retratando, por sua vez, a "materialização das lembranças, inquietações, desejos, conflitos, projetos, vivências, dúvidas e incertezas" (ESCUDERO; NEIRA, 2011, p. 300). Nesse sentido, é possível expandir o repertório por intermédio de diferentes experiências formativas que tendem a interferir no processo educacional do aluno (HOFFMANN, 2006). Contudo, deve-se atentar para que essa avaliação não se torne reducionista, já que os pontos registrados podem fundamentar a avaliação como um instrumento de medida e não de aprendizado (PAULA et al., 2018).

Para além da diversificação de recursos avaliativos, recomenda-se observar as dimensões que envolvem o conhecimento, conforme formulações teóricas de Coll et al. (2000) e Zabala (1998). Nessa esteira, Darido (2012) ressalta sobre a necessidade do fortalecimento 
da dimensão conceitual - notadamente nos domínios da Educação Física, mas não apenas -, partindo da premissa de que explicações gerais para grandes grupos podem favorecer a aplicação da avaliação conceitual. Contudo, parece oportuno ressaltar que tal procedimento de ensino poderá (quiçá) ser um método eficiente, desde que o professor proponha soluções de problemas ao invés de apenas reproduzir conceitos (HOFFMANN, 2006).

Do mesmo modo que, ao explorar a dimensão procedimental do conteúdo, as avaliações permitir-se-iam explorar a diversidade de experiências corporais. Sob essa dimensão é possível avaliar recorrendo a recursos como: construção de vivências e apresentações coletivas que envolvem práticas corporais; representações (júri simulado); pesquisas; análise de documentários ou de obras cinematográficas; produções autorais; confecções de materiais; apresentações e/ou exposições; entre tantas outras possibilidades (DARIDO, 2012).

Há ainda a dimensão atitudinal dos conteúdos, que diz respeito à construção de valores de referência. No interior dessa dimensão são tematizados: sentimentos, atitudes, valores, limites e possibilidades, que, ao serem abordados, suscitam uma formação ética e cidadã (DARIDO, 2012).

Embora tenhamos enfatizado algumas das particularidades da Educação Física, tendo em vista seu objeto de ensino, a cultura corporal de movimento, há semelhança de que muitas das questões levantadas possam ser aduzidas para os demais componentes curriculares, tal qual o processo de letramento e alfabetização, já que, em grande medida, as provocações recaem em desestabilizar condutas, instrumentos e acepções assentados nos ideais da escola tradicional, que instituem formas de exame restritas à quantificação de uma nota, sob o argumento do castigo e punição. Trata-se de crenças e representações (sociais) ainda fortemente vívidas no interior das práticas educativas atualmente.

A esse respeito, Paula et al. (2018, p. 7) anotam que:

[...] o problema a ser enfrentado na avaliação não é o do instrumento que gera uma nota ou o uso ou não de provas e trabalhos, mas a necessidade de mudanças epistemológicas a respeito desses instrumentos, orientando-nos para a necessidade de qualificarmos tanto os processos de ensino como os de aprendizagens. Para isso, é preciso entender que a avaliação se constitui como ato político e que gera compromissos éticos com aqueles envolvidos no processo.

Para Hoffmann (1994), apesar das influências teóricas abordadas no decurso do processo de formação, o estudante, ao administrar o ato da docência, muitas vezes se baseia nos métodos utilizados quando ele ainda era discente. Entretanto, o estudo de Dos Santos et al. (2016) propôs uma releitura das experiências avaliativas com professores, que no ano de 2011 estavam na condição de alunos, por efeito dessa experiência, os mesmos passaram a observar e compreender a avaliação vivenciada em sua formação inicial de outra maneira, ao passo de reconhecerem a necessidade da diversificação (de recursos), do mesmo modo a valoração do saber advindo do componente curricular em evidência, um expressivo avanço na direção de um olhar mais elaborado sobre o que é o avaliar (DOS SANTOS; MAXIMIANO, 2013).

Nessa esteira de reflexão sobre o repensar da avaliação e dos processos avaliativos, a investigação desenvolvida por Paula et al. (2018) expôs que a maioria de 45 alunos, 
integrantes de sete universidades federais, disse não possuir conhecimento de como eram avaliados na Educação Básica. Para Darido (2012) e Carminatti e Borges (2012), o que se observa é que, em muitos casos, os processos avaliativos são ocultados dos alunos, ou seja, o professor adota um método avaliativo que considera eficiente para mensurar a aprendizagem e os mais interessados nesse processo, muitas vezes, não são sequer informados por quais instrumentos serão avaliados. Trata-se de um ocultamento "pedagógico" que encobre fragilidades formativas e procedimentos de ensino ultrapassados, que sutilmente se alastram sob os ambientes pedagógicos (MATSUMOTO; AYOUB, 2018).

Na continuidade do trabalho, discorreremos acerca de outra categoria encontrada neste estudo.

\section{BALANÇO DE PROdUÇão}

De acordo com Dos Santos et al. (2018), autores que realizaram a revisão sistemática em periódicos entre 1932 e 2014 até meados de 1970, as produções sobre a Avaliação eram voltadas apenas para a mensuração do processo educacional, algo que, conforme já ponderamos, no interior da Educação Física tinha como objetivo a classificação dos corpos mediante a aptidão física, não considerando o contexto social e as diversas experiências culturais e corporais dos indivíduos (SOARES et al., 1992). A partir desse momento, contudo, Dos Santos et al. (2018) verificam uma transformação na maneira de pensar a Avaliação em Educação Física, em virtude do aprofundamento das discussões acadêmicas a respeito dessa temática preocupadas com fundamentação científica, a fim de superar as práticas adotadas até então (normalmente negligentes), propondo como alternativa uma avaliação global que fornecesse informações necessárias para o processo de ensino e aprendizagem do aluno como um todo (DOS SANTOS et al., 2018; CUPOLINO, 2018).

Em que pese tal compreensão histórica estar vinculada à subárea da Educação Física, entendemos que ela esteja imbricada com a área da Educação, mesmo porque "a produção sobre avaliação na Educação Física escolar acompanha os debates do campo da Educação, de modo atento às demandas colocadas por essa área". Há, portanto, uma necessidade pedagógica para se pensar a Educação Física e seus processos avaliativos, cuja implicação coloque em diálogo ambas as áreas (DOS SANTOS et al., 2018, p. 19).

Tomamos como evidência para isso afirmar o fato de que grande parte das pesquisas sobre a temática da Avaliação em Educação Física tem como referência autores do campo da Educação, como: Jussara Hoffman, Cipriano Luckesi, Celso Vasconcelos, Ana Maria Saul e Maria Teresa Esteban, entre outros. Esse é o caso de Suraya Darido e Wagner dos Santos, ambos são referências em pesquisas quando o assunto é avaliação no âmbito da Educação Física, contudo, recorreram à ancoragem teórica dos estudiosos supracitados do campo da Educação, para então formular suas discussões e proposições acerca da avaliação na subárea (DOS SANTOS et al., 2018). 


\section{CONSIDERAÇões FINAIS}

A temática da Avaliação perpassa as atividades desenvolvidas na instituição escolar, em tese, ela orienta as políticas, docentes, discentes, pais e todos os indivíduos envolvidos, de alguma forma, no cotidiano escolar. No campo científico da Educação, apesar de recente, tal temática também está organizada no contexto atual, notadamente em função da produção de pesquisas a respeito de experiências desenvolvidas nas escolas; no âmbito da Educação Física, sua presença é recente e menos organizada, por uma série de razões de ordem epistemológica, algumas, inclusive, foram aqui expostas.

Tal cenário só foi possível de ser construído, no entanto, a partir do momento em que nos debruçamos a respeito das produções científicas acerca da Avaliação no contexto da Educação Física desenvolvida na instituição escolar. A ideia central do artigo era proporcionar uma leitura panorâmica daquilo que vem sendo produzido, do mesmo modo sinalizar quanto à necessidade de investigações dedicadas ao mote, por efeito mapear as tendências dessas produções científicas no âmbito da Educação Física. Para tanto, fizemos uso de uma metodologia mista de pesquisa para analisarmos os números (referentes aos artigos publicados em periódicos científicos da Educação e da Educação Física sobre Avaliação) e o conteúdo para tipificar tais produções.

Num primeiro momento, identificamos que o número de artigos sobre Avaliação veiculados por revistas científicas altamente estratificas, segundo o Qualis CAPES, é relativamente restrito e obedece a um conjunto hierárquico de descritores (avaliação da aprendizagem, avaliação em Educação Física e processos avaliativos, respectivamente). Verificou-se, além disso, que as produções científicas sobre o tema em questão vêm se intensificando na última década, sendo que a incidência maior encontra-se ao abrigo do descritor: "Procedimentos e Experiências Avaliativas", seguido daquelas sob o agrupamento: "Currículo e Documentos Institucionais" e, por fim, têm-se aquelas reunidas à sombra de procedimentos investigativos de "Balanço de Produção", o que, de certo modo, ratifica a assertividade da escolha metodológica do estudo que empreendemos.

Corolário a isso, analisamos os respectivos agrupamentos, por efeito identificou-se no que concerne aos "Procedimentos e Experiências Avaliativas" que, normalmente, existe a preocupação nos artigos com aquilo que determina epistemologicamente o sentido da Avaliação, malgrado, ainda na Educação Física, mas não apenas, encontrarmos certa resistência em relação à utilização de recursos diversificados, mais globais e qualitativos, em detrimento à quantificação, muito provavelmente em razão dos limites decorrentes dos processos formativos, somados à natureza conservadora das instituições de ensino; no que se refere ao "Currículo e Documentos Institucionais" constatou-se se tratar de um debate em curso, apesar de tímido no interior do processo de formação de professores de Educação Física e que, mesmo considerando, os currículos escolares ainda se observa certa escassez de discussões no que diz respeito ao tema da Avaliação; por fim, sobre os estudos assentados sob pressupostos metodológicos de "balanços de produção" averiguou-se certo avanço ao campo da Avaliação em Educação Física, em função das suas próprias transformações históricas, demovendo-se (em alguma medida) da acepção biológica - no sentido da aptidão física (ter ou não) - e assentando-se sob ideais pedagógicos, sobre os quais se encontra o contexto educacional. 
Cabe salientar, ainda, que apesar das informações produzidas e aqui veiculadas serem datadas historicamente, em função da natureza do próprio texto e a pesquisa que ele retrata, ao mesmo tempo confere um olhar panorâmico sobre determinado momento histórico, na tentativa de lançar rebento acerca do fenômeno estudado. Ademais, como modelo heurístico, tal estudo pode representar um ponto de partida para o desenvolvimento de outras pesquisas que considerem critérios de análise diferentes.

\section{REFERÊNCIAS}

AYOUB, Eliana. Reflexões sobre a educação física na educação infantil. Revista Paulista de Educação Física, supl. 4, p. 53-60, 2001.

BARATA, Rita de Cássia Barradas. Dez coisas que você deveria saber sobre o Qualis. Revista Brasileira de Pós-Graduação, v. 13, n. 30, p. 13-40, 2016.

BARDIN, Laurence. Análise de conteúdo, 5. ed. Lisboa: Edições 70, 2009.

BERTAGNA, Regina Helena; SORDÍ, Mara Regina Leme. Avaliação Educacional: um campo em movimento e disputa. Cadernos Cedes, v. 36, n. 99, p. 129-133, 2016.

BETTI, Mauro. Educação física escolar: ensino e pesquisa-ação, 2. ed. Ijuí: Unijuí, 2013.

BETTI, Mauro. Educação Física e sociedade. São Paulo: Movimento, 1991.

BETTI, Mauro. Imagens em avalia-ação: uma pesquisa-ação sobre o uso de matérias televisivas em aulas de Educação Física. Educar em Revista, n. esp. 2, p. 137-152, 2010.

CARBINATTO, Michele Viviene et al. Avaliação em Dança: o caso dos festivais universitários da Educação Física. Pro-posições, v. 27, n. 3, p. 57-80, 2016.

CARBINATTO, Michele Viviene; NUNOMURA, Myrian. Gymnastics in higher education: reflections on assessment. Revista Brasileira de Educação Física e Esporte, v. 30, n. 1, p. 171-181, 2016.

CARLOMAGNO, Márcio C.; DA ROCHA, Leonardo Caetano. Como criar e classificar categorias para fazer análise de conteúdo: uma questão metodológica. Revista Eletrônica de Ciência Política, v. 7, n. 1, 2016.

CARMINATTI, Simone Soares Haas; BORGES, Martha Kaschny. Perspectivas da avaliação da aprendizagem na contemporaneidade. Estudos em Avaliação Educacional, v. 23, n. 52, p. 160-178, 2012.

CARNEIRO, Kleber Tuxen; ASSIS, Eliasaf Rodrigues de; BRONZATTO, Maurício. Da necessidade à negação: a percepção da crise epistemológica na educação física a partir da 
compreensão docente. Revista Brasileira de Ciência e Movimento, v. 24, n. 4, p. 129$142,2016$.

COLL, C. et al. Os conteúdos na reforma. Porto Alegre: ARTMED, 2000.

COORDENAÇÃO DE APERFEIÇOAMENTO DE PESSOAL DE NÍVEL SUPERIOR - CAPES. Classificação da produção intelectual, 2009. Disponível em: <http://www.capes.gov.br/avaliacao/instrumentos-de-apoio/classificacao-da-producao-intelectual $>$, acesso em: 16 abr. 2019.

CORREIA, Anna Elizabeth Galvão Coutinho; ALVARENGA, Lídia; GRACIA, Joana Coeli Ribeiro. Produção científica: reflexos da avaliação nos programas de pós-graduação em física. Em Questão, v. 18, n. 3, p. 231-247, 2012.

CRESWELL, John W.; CLARK, Vicki L. Plano. Pesquisa de Métodos Mistos: Série Métodos de Pesquisa, 2. ed. Porto Alegre: Penso Editora, 2013.

CUPOLILLO, Amparo Villa. Avaliação da aprendizagem escolar e a educação física: processos regulatórios e possibilidades emancipatórias. Revista de Educação PUC-Campinas, n. 25, p. 25-34, 2008.

DAÓLIO, Jocimar. Da cultura do Corpo. Campinas: Editora Papirus, 2004.

DARIDO, Suraya Cristina. Educação física na escola: realidade, aspectos legais e possibilidades. In: UNIVERSIDADE ESTADUAL PAULISTA. Prograd. Caderno de formação: formação de professores didática geral. São Paulo: Cultura Acadêmica, v. 16, p. 21-33, 2012.

DAVINI, Maria Cristina et al. Currículo integrado. In: BRASIL. Ministério da Saúde. Coordenação Geral de Desenvolvimento de Recursos Humanos para o SUS. Capacitação pedagógica para instrutor/supervisor-área da saúde. Brasília: Ministério da Saúde, p. 281289, 1994.

DINIZ, Josiane; AMARAL, Sílvia Cristina Franco. A avaliação na educação física escolar: uma comparação entre as escolas tradicional e ciclada. Movimento, v. 15, n. 1, p. 241-258, 2009.

DOS SANTOS, Wagner et al. Avaliação em educação física escolar: trajetória da produção acadêmica em periódicos (1932-2014). Movimento, v. 24, n. 1, p. 09-22, 2018.

DOS SANTOS, Wagner et al. Narrativas docentes sobre avaliação do ensino-aprendizagem: da formação inicial ao contexto de atuação profissional. Movimento, v. 22, n. 3, p. 779-352, 2016. 
DOS SANTOS, Wagner; DE LIMA MAXIMIANO, Francine. Memórias discentes em educação física na educação básica: práticas avaliativas. Movimento, v. 19, n. 2, p. 79-101, 2013.

DUARTE, Emeide Nóbrega et al. Estratégias metodológicas adotadas nas pesquisas de iniciação científica premiadas na UFPB. Encontros Bibli: Revista Eletrônica de Biblioteconomia e Ciência da Informação, v. 14, n. 27, p. 170-190, 2009.

ESCUDERO, Nyna Taylor Gomes; NEIRA, Marcos Garcia. Avaliação da aprendizagem em educação física: uma escrita autopoiética. Estudos em Avaliação Educacional, v. 22, n. 49, p. 285-304, 2011.

FERNANDES, Domingos. Vinte e cinco anos de avaliação das aprendizagens: uma síntese interpretativa de livros publicados em Portugal. In: ESTRELA, A. (Org.). Investigação em educação: teorias e práticas (1960-2005). Lisboa: Editora Educa, p. 261-306, 2007.

FRANCO, Maria Laura Puglisi Barbosa. Análise do conteúdo, 3. ed. Brasília: Liber Livro Editora, 2008.

FREIRE, João Batista. Educação de corpo inteiro: teoria e prática da Educação Física. São Paulo: Scipione, 1997.

GATTI, Bernardete A. Avaliação educacional no Brasil: pontuando uma história de ações. EccoS Revista Científica, v. 4, n. 1, p. 17-41, 2002.

HOFFMANN, Jussara. Avaliar para promover: as setas do caminho, 8. ed. Porto Alegre: Mediação, 2006.

HOFFMANN, Jussara Maria Lerch. Avaliação mediadora: uma relação dialógica na construção do conhecimento. Ideias. Avaliação do rendimento escolar. São Paulo: FDE, p. 51-59, 1994.

JOHNSON, R. Burke; ONWUEGBUZIE, Anthony J.; TURNER, Lisa A. Toward a definition of mixed method research. Journal of Mixed Methods Research, v. 1, n. 2, p. 112-133, 2007.

LARROSA, Jorge Bondia. Notas sobre a experiência e o saber de experiência. Revista brasileira de educação, n. 19, p. 20-28, 2002.

LE BOULCH, J. O desenvolvimento psicomotor: do nascimento até 6 anos. Porto Alegre: Artes Médicas, 1992.

Lei das Diretrizes e Bases, disponível em: http://www.planalto.gov.br/ccivil_03/LEIS/ L9394.htm, acesso em: 22 mar. 2019. 
LUCKESI, Cipriano Carlos. Avaliação da aprendizagem na escola e a questão das representações sociais. EccoS Revista Científica, v. 4, n. 2, p. 79-88, 2002.

LUCKESI, Cipriano Carlos. O que é mesmo o ato de avaliar a aprendizagem. Revista Pátio, v. 3, n. 12 , p. 6-15, 2000.

MATSUMOTO, Marina Hisa; AYOUB, Eliana. Avaliação na Educação Física escolar: Entre o prescrito e o vivido. Pro-posições, v. 29, n. 3, p. 229-253, 2018.

MELO, Luciene Farias de et al. O portfólio como possibilidade de avaliação na educação física escolar. Revista da Educação Física, v. 21, n. 1, p. 87-97, 2010.

NEIRA, Marcos Garcia; JÚNIOR, Marcílio Souza. A Educação Física na BNCC: procedimentos, concepções e efeitos. Motrivivência, v. 28, n. 48, p. 188-206, 2016.

PAULA, Sayonara Cunha et al. Avaliação da Educação Física na Educação Básica: diálogos com alunos de sete universidades federais. Journal of Physical Education, v. 29, n. 1, p. 1-14, 2018.

PAULA, Sayonara Cunha et al. Ensino da avaliação nos cursos de Educação Física da América Latina. Estudos em Avaliação Educacional, v. 29, n. 72, p. 802-830, 2018.

RODRIGUES, Eloy et al. RepositóriUM: criação e desenvolvimento do Repositório Institucional da Universidade do Minho. Actas do Congresso Nacional de Bibliotecários, Arquivistas e Documentalistas. n. 8, 2004.

SILVA, Luciana Maria Fernandes; RUFINO, Luiz Gustavo Bonatto; DARIDO, Suraya Cristina. Capoeira e temas transversais: avaliação de um blog didático para as aulas de educação física. ETD-Educação Temática Digital, v. 15, n. 1, p. 87-106, 2013.

SOARES, Carmen Lúcia et al. Metodologia do Ensino de Educação Física. São Paulo: Cortez, 1992.

SOARES, Everton Rocha. Educação Física no Brasil: da origem até os dias atuais. Lecturas: Educación Física y Deportes, n. 169, p. 1-5, 2012.

STIEG, Ronildo et al. Avaliação educacional nos cursos de licenciatura em educação física nas IES brasileiras: uma análise das disciplinas específicas. Currículo Sem Fronteiras, v. 18, n. 2, p. 639-667, 2018.

TANI, Go et al. Educação Física escolar: fundamentos de uma abordagem desenvolvimentista. São Paulo: EPU, 1988. 
VARGAS, Cláudio Pellini. Avaliação na educação física escolar: tensões para além das epistemologias. Revista Brasileira de Educação Física e Esporte, v. 31, n. 4, p. 819-834, 2017.

ZABALA, Antoni. A prática educativa. Porto Alegre: ArtMed, 1998.

\section{DADOS DOS AUTORES:}

\section{Fabiana de Paula Pereira}

Mestranda em Educação. fabipereeira16@gmail.com

\section{KLeber Tuxen Carneiro}

Doutor em Educação Escolar pela Universidade Estadual Paulista "Júlio de Mesquita Filho". Pós-Doutorando em Educação pela Universidade Estadual de Campinas. Docente do Pós Graduação em Educação na Universidade Federal de Lavras, Lavras/MG-Brasil. kleber2910@gmail.com

\section{Bruno Adriano Rodrigues da SiLva}

Doutor em Educação, com Estágio de Pós-Doutoramento pela Universidade Federal do Estado do Rio de Janeiro. Professor adjunto da Universidade Federal de Lavras, Lavras/ MG-Brasil.b.adriano_rs@yahoo.com.br

\section{Fábio Pinto Gonçalves dos Reis}

Doutor pela Universidade de São Paulo. Professor associado da Universidade Federal de Lavras, Lavras/MG-Brasil. fabioreis@ufla.br

\section{Nathália Maria Resende}

Doutora em Ciências pela Universidade Federal de Minas Gerais. Professora adjunta da Universidade Federal de Lavras, Lavras/MG-Brasil.e professora colaboradora do Programa de Pós-Graduação em Ciências da Saúde da Universidade Federal de Minas Gerais/ MG-Brasil.nathalia.resende@ufla.br

Submetido em: 15-8-2019

Aceito em: 6-8-2020 